\title{
Effect of ultrasound on the dissolution of Mardin-Mazıdağı (Turkey) phosphate ore in dilute $\mathrm{H}_{3} \mathrm{PO}_{4}$ solutions
}

\author{
M. Sinirkaya \\ Department of Chemical Engineering, Atatürk University, 25240 Erzurum, Turkey
}

Received May 18, 2017; Accepted January 3, 2018

\begin{abstract}
The dissolution of phosphate ore in dilute phosphoric acid solutions was investigated in both the absence and presence of ultrasound. Acid concentration, reaction temperature and reaction time were chosen as parameters. While the conversion fractions decreased with increasing temperature in dilute phosphoric acid in absence of ultrasound, these rates increased with increasing temperature in the presence of ultrasound. In the experiments, the expected effects of ultrasound were observed, such as decrease in the thickness of the diffusion layer on the solid-liquid interfaces in the suspension, leading to increased surface area.
\end{abstract}

Key words: Phosphate rock, Phosphoric acid, Dissolution kinetics, Ultrasound, Cavitation

\section{INTRODUCTION}

Most of the phosphorus in the phosphate rock is found as fluorapatite $\mathrm{CaF}_{2}\left(\mathrm{PO}_{4}\right)_{6}$, which is a stable compound that can not be easily supplied as a plant nutrient. In order to obtain available phosphorus it is necessary to destroy the fluorapatite structure of the phosphate rock and to form soluble compounds in the soil solutions. This may be accomplished by acid treatment or by thermal treatment. The treatment of the phosphate rock with acids such as sulfuric or phosphoric acid is commonly used for the production of normal or triple superphosphates [1]. The phosphate rock composition changes from one deposit to another. Therefore, phosphate rock from different sources is expected to behave differently in acidulation processes, which are the basis of the phosphate fertilizer industry. The phosphatic formations in Mazıdağ 1 were investigated. It was found that these phosphorite deposits occurred as a result of the following steps: erosion of calcitized deposits, redeposition in a phosphatizing environment, phosphatization of this detritus material and weathering causing an enrichment of the ores [2]. The Mazıdağı phosphate rock mainly consists of calcite, fluorapatite and carbonate-fluorapatite [3].

Acidic dissolution of natural phosphate rocks is a basic process in the production of inorganic phosphorus fertilizers, such as superphosphate (mono and double), wet-process phosphoric acid (the main semiproduct for subsequent fabrication of various kinds of inorganic fertilizers, e.g., ammonium phosphate or amorphous), nitroamorphous, and other complex and mixed fertilizers $[4,5]$. The phosphate ores used in wet

\footnotetext{
* To whom all correspondence should be sent:

E-mail: melikesinirkaya@gmail.com
}

processes today are mainly sedimentary phosphates or francolites. They are mainly produced by digestion of phosphate ore (fluorapatite) with sulfuric acid. This yields phosphoric acid as a product and hydrated calcium sulfate as a byproduct. The ore also contains traces of heavy metal ions, the most worrisome of which are cadmium and radium. They can cause serious environmental problems. When a mixture of phosphoric acid and sulfuric acid is used for the digestion of the ore, two processes occur more or less simultaneously: digestion of the ore and precipitation of calcium sulfate hemihydrate. At high sulfate concentrations, the calcium sulfate tends to precipitate not only upon the hemihydrate crystals but also upon the ore particles. Such a coating is often called blinding [6].

Ultrasound has been successfully used to enhance the rates of mass transfer and reaction in several homogeneous $[7,8]$ and heterogeneous $[9,10]$ media. The true chemical effects of ultrasound are attributed to the implosive collapse of microbubbles which are formed during the rarefaction, or negative pressure period, of sound waves. The implosive collapse of microbubbles, typically referred to as cavitation, results in a variety of mechanical effects as well. When solid particles are in the vicinity of the cavitation bubble, the implosion may occur symmetrically, depending on the proximity of the solids. Symmetric cavitations create shock waves which propagate to the surrounding solid causing microscopic turbulence and thinning of the solid-liquid film. This phenomenon is called microstreaming and is believed to be responsible for increasing the mass transfer rate of the reactants and products through the film [11]. 
M. Sinırkaya: Effect of ultrasound on the dissolution of Mardin-Mazıdağ (Turkey) phosphate ore in dilute $\mathrm{H}_{3} \mathrm{PO}_{4} \ldots$

Table 1. Analysis of the phosphate rock samples (wt\%)

\begin{tabular}{|ccccc|}
\hline Components & $710-1000 \mu \mathrm{m}$ & $500-710 \mu \mathrm{m}$ & $355-500 \mu \mathrm{m}$ & $250-355 \mu \mathrm{m}$ \\
\hline $\mathrm{CaO}$ & 50.50 & 50.27 & 50.18 & 50.36 \\
\hline $\mathrm{P}_{2} \mathrm{O}_{5}$ & 22.34 & 23.27 & 24.53 & 25.09 \\
\hline $\mathrm{MgO}$ & 1.59 & 1.6 & 1.59 & 1.62 \\
\hline $\mathrm{Fe}_{2} \mathrm{O}_{3}$ & 0.01 & 0.03 & 0.04 & 0.06 \\
\hline $\mathrm{Al}_{2} \mathrm{O}_{3}$ & 1.14 & 1.13 & 1.13 & 1.14 \\
\hline $\mathrm{SiO}_{2}$ & 4.26 & 4.05 & 3.34 & 2.86 \\
\hline $\mathrm{F} 2$ & 3.28 & 3.6 & 3.77 & 3.85 \\
\hline Loss on & 15.41 & 14.85 & 13.86 & 13.09 \\
ignition $\left(\mathrm{CO}_{2}\right)$ & $(12.06)$ & $(11.23)$ & $(8.57)$ & $(6.98)$ \\
\hline
\end{tabular}

Zhu et al. discovered that ultrasound could improve gold extraction from refractory gold ores by reducing the diffusion resistance and enhance the gold leaching rate [12]. Zhang et al. observed that the leaching rates of $\mathrm{Sb}$ and $\mathrm{Pb}$ in lead-rich and antimony-rich oxidizing slag were significantly improved by using ultrasound radiation and the reaction time was sharply shortened [13]. Avvaru et al. [14] found that the ultrasound clearly improved the uranium leaching rate in nitric acid and sulfuric acid solutions. Shen et al. [15] employed hightemperature ultrasonic acid leaching to improve the extraction of indium from blast furnace sludge compared with that without ultrasonic assistance. They found that ultrasound had a positive effect on the rate of leaching. The purpose of this work was to investigate the effect of ultrasonic energy on the dissolution of phosphate ore in dilute $\mathrm{H}_{3} \mathrm{PO}_{4}$ solutions.

$$
\begin{aligned}
& \mathrm{C}_{\mathrm{a} 10}\left(\mathrm{PO}_{4}\right)_{6} \mathrm{~F}_{2}+4 \mathrm{H}_{3} \mathrm{PO}_{4} \rightarrow 10 \mathrm{CaHPO}_{4}+2 \mathrm{HF} \\
& \mathrm{Ca}_{10}\left(\mathrm{PO}_{4}\right)_{6} \mathrm{~F}_{2}+14 \mathrm{H}_{3} \mathrm{PO}_{4} \rightarrow 10 \mathrm{Ca}\left(\mathrm{H}_{2} \mathrm{PO}_{4}\right)_{2}+2 \mathrm{HF}
\end{aligned}
$$

\section{EXPERIMENTAL PROCEDURE}

Phosphate rock samples were obtained from Mardin-Mazıdag1 phosphate rock concentration plant, Turkey. The sample was crushed, ground, and then sieved to give 250-355, 355-500, 500710 and $710-1000 \mu \mathrm{m}$ size fractions using ASTM standard sieves. The chemical analysis of the phosphate rock was carried out by standard gravimetric, volumetric, and spectrometric methods, and the results of chemical analysis are given in Table 1.

The dissolution experiments were carried out with phosphate samples having particle sizes of 500-710 $\mu \mathrm{m}$. The set-up for dissolution experiments is shown in Fig. 1. It consists of an ultrasonic generator (Cole Parmer, Ultrasonic homogenizer, $400 \mathrm{~W}, 20 \mathrm{kHz}$ ), a probe with tip radius of $1 \mathrm{~cm}$ and a thermocouple. The probe was covered with a Teflon band for hindering the probable corrosion of the probe in the $\mathrm{H}_{3} \mathrm{PO}_{4}$. Five hundred $\mathrm{ml}$ of phosphoric acid solution prepared from different concentrations of chemically pure phosphoric acid (85 mass $\% \mathrm{H}_{3} \mathrm{PO}_{4}$ ) and distilled water were placed in a batch reactor and heated to the desired temperature. For each run, $5 \mathrm{~g}$ of phosphate sample was quickly transferred into the reactor. A 3-ml sample was withdrawn from the reactor at predetermined time intervals and was filtered immediately. The $\mathrm{CaO}$ content of the filtrate was analyzed by volumetric titration [16].

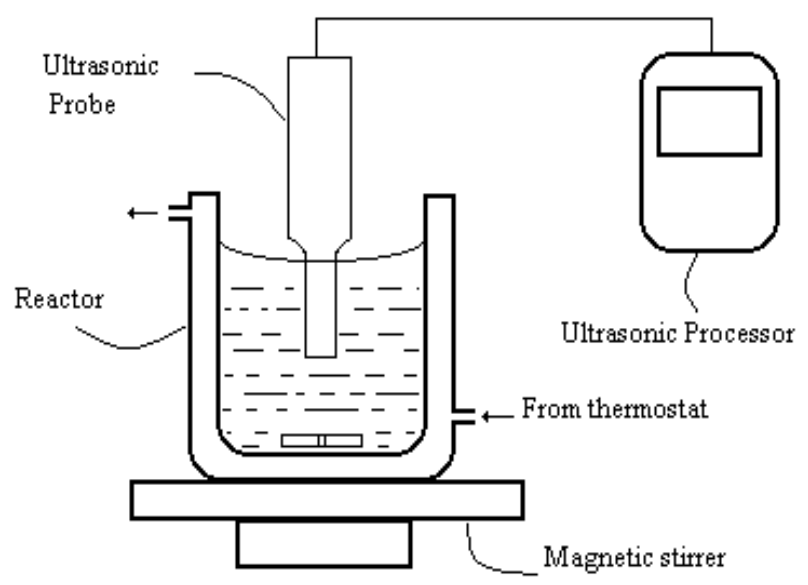

Figure 1. Scheme of the experimental set-up for dissolution.

\section{RESULTS AND DISCUSSION}

In this study, the effects of the temperature and phosphoric acid concentration on the dissolution rate were investigated in both the presence and absence of ultrasound. Experiments were performed for the concentrations of $0.1 \mathrm{M}, 0.25 \mathrm{M}$ and $0.5 \mathrm{M}$ at reaction temperatures of 30,50 and $75^{\circ} \mathrm{C}$, a stirring speed of $800 \mathrm{rpm}$ and a particle size of $500-710 \mu \mathrm{m}$. The results of the experiments in the absence of ultrasound are shown in Figs. 2, 4 and 6.

It is seen that the dissolved fraction decreased with increasing temperature, as shown in Figs. 2 and 4. The phosphoric acid used for the digestion is a recycled product acid and $\mathrm{CaHPO}_{4}$ forms at a low acid concentration. This layer is stronger at high temperatures $[17,18]$. That is why the lowest $\mathrm{CaO}$ conversion in absence of ultrasound was obtained at 
M. Sinırkaya: Effect of ultrasound on the dissolution of Mardin-Mazıdağ (Turkey) phosphate ore in dilute $\mathrm{H}_{3} \mathrm{PO}_{4} \ldots$

$75^{\circ} \mathrm{C}$ and this ratio was found to be $40.75 \%$ in 0.1 $\mathrm{M}$ phosphoric acid solution for 30 min reaction time, as shown in Fig 2.

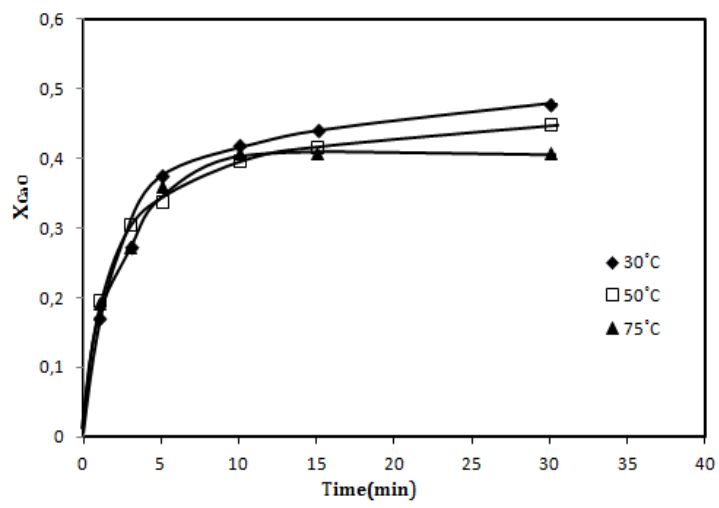

Figure 2. Effect of reaction temperature on the dissolution of $\mathrm{CaO}$ in $0.1 \mathrm{M}\left(0.71\right.$ wt $\left.\% \mathrm{P}_{2} \mathrm{O}_{5}\right)$ phosphoric acid in the absence of ultrasound.

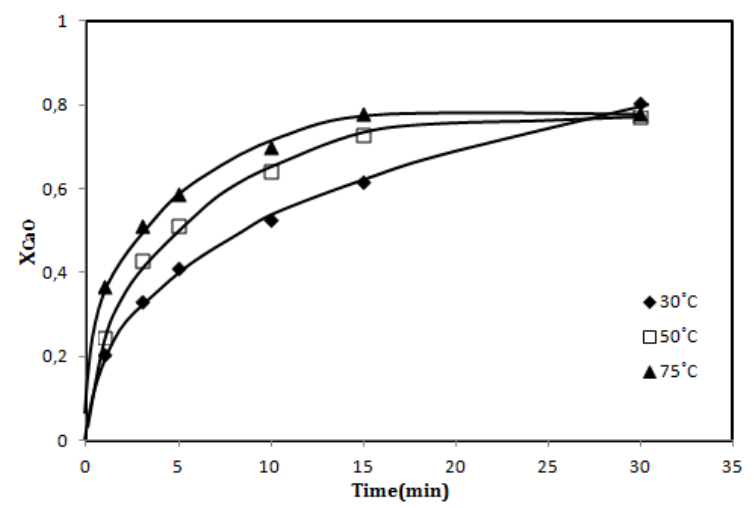

Figure 4. Effect of reaction temperature on the dissolution of $\mathrm{CaO}$ in $0.25 \mathrm{M}\left(1.76\right.$ wt $\left.\% \mathrm{P}_{2} \mathrm{O}_{5}\right)$ phosphoric acid in the absence of ultrasound.

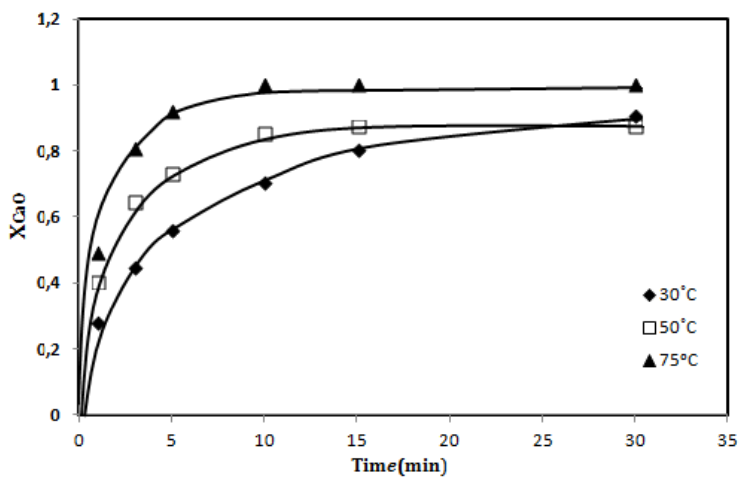

Figure 6. Effect of reaction temperature on the dissolution of $\mathrm{CaO}$ in $0.5 \mathrm{M}\left(3.97\right.$ wt $\left.\% \mathrm{P}_{2} \mathrm{O}_{5}\right)$ phosphoric acid in the absence of ultrasound.

The solubility increased with increasing acid concentration. As the concentration of $\mathrm{H}_{3} \mathrm{PO}_{4}$ increased, the dissolved fraction of $\mathrm{CaO}$ increased in both the absence and presence of ultrasound. As the concentration of $\mathrm{H}_{3} \mathrm{PO}_{4}$ increased, the migration of $\mathrm{Ca}^{+2}$ ions from the ash film $\left(\mathrm{CaHPO}_{4}\right)$ to the liquid medium increased.
The experimental results with ultrasound are shown in Figs. 3, 5 and 7. In these experiments the solubility increased with increasing reaction temperature.

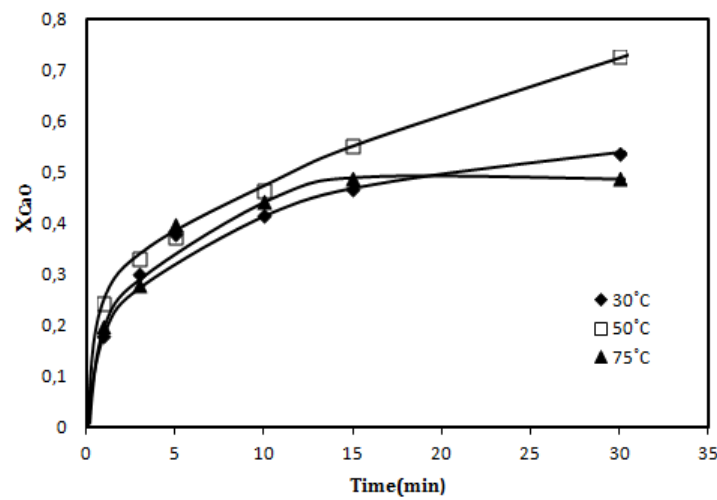

Figure 3. Effect of reaction temperature on the dissolution of $\mathrm{CaO}$ in $0.1 \mathrm{M}\left(0.71 \mathrm{wt} \% \mathrm{P}_{2} \mathrm{O}_{5}\right)$ phosphoric acid in the presence of ultrasound.

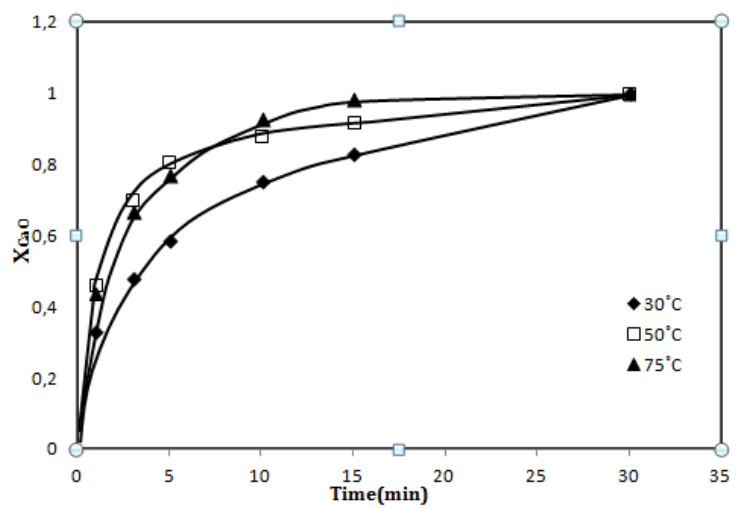

Figure 5. Effect of reaction temperature on the dissolution of $\mathrm{CaO}$ in $0.25 \mathrm{M}\left(1.76\right.$ wt $\left.\% \mathrm{P}_{2} \mathrm{O}_{5}\right)$ phosphoric acid in the presence of ultrasound.

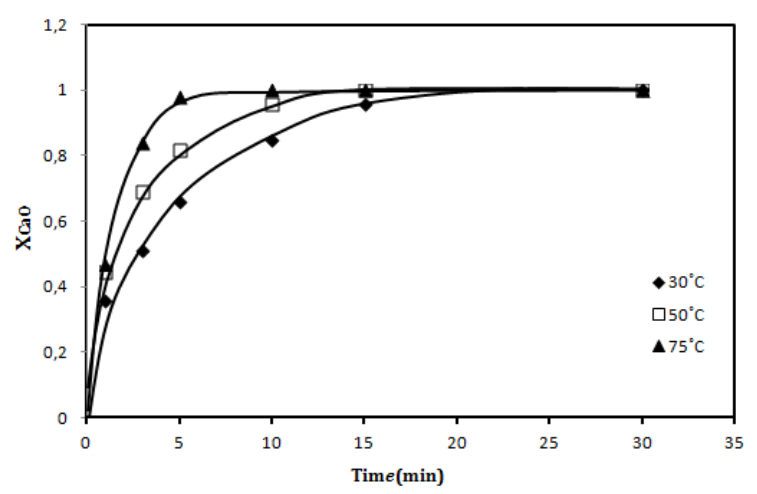

Figure 7. Effect of reaction temperature on the dissolution of $\mathrm{CaO}$ in $0.5 \mathrm{M}\left(3.97\right.$ wt $\left.\% \mathrm{P}_{2} \mathrm{O}_{5}\right)$ phosphoric acid in the presence of ultrasound.

The dissolved fraction of $\mathrm{CaO}$ in presence of ultrasound increased because the ash layer thickness $\left(\mathrm{CaHPO}_{4}\right)$, which reduces the dissolution rate, decreased with increasing time. Hagenson and Doraiswamy observed that ultrasound could enhance the rates of mass transfer and reaction in heterogeneous systems, since ultrasound caused a 
M. Sinırkaya: Effect of ultrasound on the dissolution of Mardin-Mazıdağ (Turkey) phosphate ore in dilute $\mathrm{H}_{3} \mathrm{PO}_{4} \ldots$ decrease in the diffusion layer thickness on the solid-liquid interfaces in the suspension [11]. As shown in Figure 2, the dissolution rate of $\mathrm{CaO}$ was $45.04 \mathrm{wt} \%$ for $30 \mathrm{~min}$ at $50^{\circ} \mathrm{C}$ in the absence of ultrasound, whereas, this rate was $72.54 \mathrm{wt} \%$ at the same conditions in the presence of ultrasound (Fig. $3)$.

\section{CONCLUSIONS}

In this study, the dissolution kinetics of phosphate ore from Mardin-Mazıdaği, Turkey, in dilute phosphoric acid solutions was investigated in both the presence and absence of ultrasound. The precipitation of $\mathrm{CaHPO}_{4}$ on the mineral surface created difficulty for $\mathrm{H}_{3} \mathrm{O}^{+}$to diffuse to the unreacted mineral surface in absence of ultrasound. According to the results of the study, the use of ultrasound increased the conversion fraction.

This result can be attributed to the reduction of the liquid film thickness around the solid particle, due to the increase in the velocity of the solid relative to the liquid velocity. The application of ultrasound has affected the controlling step of the dissolution. Our opinion is that ultrasound has enhanced the attack of $\mathrm{H}_{3} \mathrm{O}^{+}$on cationic sites on the rock which facilitates the migration of $\mathrm{Ca}^{+2}$ ions to the liquid medium.

Phosphoric acid is used for fertilizer applications. To minimize environmental pollution by heavy metals, a new process was being designed. One of the important steps in this process is the complete digestion of phosphate ore in phosphoric acid.

Phosphoric acid is a major component of many fertilizers. Since the digestion process is dominated by the diffusion of calcium ions from the surface of the ore into the bulk of the solution, no influence of impurities present in the process acid is expected. This was confirmed by using real product acid where the impurities did not hamper the digestion. Only if the impurities present in the acid (like excess sulfate ions) give rise to blinding of the ore particles can a reduction of the digestion process be expected [19]. In this study, a fast complete digestion of phosphate ore was achieved with dilute phosphoric acid solutions in presence of ultrasound at lower concentrations.

As a result, in the light of these observations, ultrasound would be a helpful tool for phosphoric acid production because the dissolution experiments performed in the presence of ultrasound needs much less phosphoric acid. Thus, the utization of ultrasound in phosphoric acid production as a product and calcium hydrogen phosphate as a byproduct not only decreases the acid consumption but also gives a useful product, which helps to eliminate environmental damages.

\section{REFERENCES}

1. G. L. Bridger, D.R. Boylan, Industrial and Engineering Chemistry, 45, 646 (1953).

2. J. Naktiyok, A. K. Özer, M.Çelik, M. Ş. Gülaboğlu, J. Chem. Soc. Pak., 35, 1138 (2013).

3. A. K. Özer, M. Ş. Gülaboğlu, S. Bayrakçeken, W. Weisweiler, Advanced Powder Technology, 17, 481 (2006).

4. W. R. Hamilton, A. R. Wooley, A. C. Bishop, Minerals, Rocks and Fossils, 4th ed., Country Life Books, Twickenham, Middlesex, England, 1987.

5. M. M. Seckler, O.S.L. Bruinsma, G.M. van Rosmalen, Water Res., 30, 1585 (1996).

6. P. Becker, Phosphate and Phosphoric Acid, Fertiliser Science and Technology Series, Marcel Dekker, New York, 1983.

7. J. Berlan, F. Trabelsi, H. Delmas, Ultrasonics Sonochem., 1, 97 (1994).

8. G. Cum, R. Gallo, A. Spadaro, J. Chem. Soc. Perkin Trans., 11, 375 (1998).

9. M.S.F. Lie Ken Jie, C.K. Lam, Ultrasonics Sonochem., 2, 11 (1972).

10. J.L. Lunche, Ultrasonics Sonochem., 1, 111 (1994).

11. L.C. Hagenson, L.K. Doraiswamy, Chemical Engineering Science, 53, 131 (1998).

12. P. Zhu, X.J. Zhang, K.F. Li, G.R. Qian, Int. J. Miner. Metall. Mater., 19, 473 (2012).

13. R. Zhang, X. Zhang, S. Tang, A. Huang, Ultrason. Sonochem., 27, 187 (2015).

14. B. Avvaru, S.B. Roy, Y. Ladola, S. Chowdhury, K.N. Hareendran, A.B. Pandit, Chem. Eng. Process., 47, 2107 (2008).

15. X.M. Shen, L.S. Li, Z.J. Wu, H.H. Lu, J. Lu, Metall. Mater. Trans. B, 44, 1324 (2013).

16. H. Gulensoy, Complexometric Titrations, Istanbul Univ. Pub., İstanbul, 1977.

17. K. L. Elmore, T.D. Farr, Ind. Eng. Chem., 32, 580 (1940).

18. M. Sinırkaya, A.K. Özer, M.S. Gulaboglu, Minerals Metallurgical processing, 27,110 (2010).

19. S. van der Sluis, Y. Meszaros, W.G.J. Marchee, H. A. Wesselingh, G. M. van Rosmalen, Ind. Eng. Chem. Res., 26, 2501 (1987). 